\title{
Predicting Abdominal Surgery Mortallity: A Model Based on Intra-abdominal Pressure
}

\author{
Caridad de Dios Soler-Morejón MD PhD, Tomás A. Lombardo-Vaillant MD MS, Teddy O. Tamargo-Barbeito MD PhD, \\ Manu L.N.G. Malbrain MD PhD
}

\begin{abstract}
INTRODUCTION Early assessment of prognosis following major abdominal surgery is associated with decreased risk of complications and death. While scoring systems are useful in this regard, there is no index that enables comprehensive individual patient assessment and is also applicable in ICUs with limited resources.
\end{abstract}

OBJECTIVES Demonstrate that a model based on intra-abdominal pressure is effective in predicting death after major abdominal surgery.

METHODS A prospective observational study was done of 300 postabdominal-surgery patients admitted to the ICU of a university hospital affiliated with the General Calixto García Medical Faculty, in January 2008 through January 2010. Patients were randomly assigned (2:1) to two groups: test and validation. The independent variable was vital status at discharge (alive or deceased); independent variables were age, sex, malignancy, APACHE II score and intra-abdominal pressure. In the test group, three mathematical models were fit to predict death (APACHE II, intra-abdominal pressure, and APACHE II plus intraabdominal pressure), which were later validated in the second group.

\section{INTRODUCTION}

Early assessment of risk of death or complications in patients undergoing major abdominal surgery (MAS) is imperative in clinical practice. Assessing prognosis enables better organization of available resources and is useful for establishing benchmarks for improving health care quality. The actual number of deaths should be close to the estimated number, or decrease as quality of care increases. Assessing prognosis is thus a useful resource for evaluation and auditing.[1] A large deviation from the predicted standard may indicate a failure in one or more steps in the health care process.

Assessing prognosis supports treatment strategies for patients who have required MAS, helping define the best options for decreasing risk of complications and death. This is especially true for patients with intra-abdominal infectious complications (IIC) requiring reoperation.[2,3] Early detection of complications notably influences improvement in outcomes.[1,4-7] However, in these patients, prognosis tends to be difficult to assess,[4] which carries the risk of a late decision to reoperate.[2,8] Most surgeons' criteria are based on clinical practice, personal experience and diagnostic tests, but this approach to decisionmaking is skills-based and therefore its reliability varies among professionals. It has been argued that routine clinical and paraclinical parameters have limited value for early IIC diagnosis.[6]

Axial tomography is the gold standard among diagnostic imaging methods for IIC detection, but the technology may not always be available, and it requires hemodynamic stability.[3]
Each model's capacity to discriminate between living and deceased was evaluated according to sensitivity and specificity of receiver operating characteristic curves. Calibration was assessed with the Hosmer-Lemeshow goodness-of-fit test and comparison of receiver operating characteristic curves by chi-square test of homogeneity. Each patient was followed until hospital discharge or death.

RESULTS The three mortality prediction models displayed excellent calibration and discrimination, very similar predictive power, and no differences among their respective areas under the curve (chi square $2.802, p=0.094$ ). Variables with the most influence on probability of death were age, APACHE II score and intra-abdominal pressure.

CONCLUSIONS The three models show good capacity and similar effectiveness to predict death after major abdominal surgery. The model based on intra-abdominal pressure is the most feasible in limited-resource settings.

KEYWORDS Abdominal surgery, APACHE II, intra-abdominal pressure, mortality, prediction model, evidence-based medicine, decision modeling, decision support techniques, Cuba

Abdominal ultrasound also has limitations in the presence of abdominal distension, intense pain, or intestinal gas.[3] More recently, biomarkers such as procalcitonin, C-reactive protein and some cytokines (such as interleukin 6 and tumor necrosis factor) have been reported useful in IIC diagnosis, $[5,6,9]$ but data on their diagnostic or prognostic value have been inconsistent. $[5,6]$ Furthermore, systematic measurement of biomarkers could increase cost of care,[6] an additional obstacle to their use in ICUs with limited budgets and resources.

Scoring systems are instruments validated by clinical research to support medical decision-making. Their advantage lies in contributing objectivity to assessment of patient status, but they are not employed systematically in all services. IIC-risk scoring systems are mainly used for comparing research results and as audit tools.[1,7] While it is hoped that they will be able to guide clinical decisions in future, they are not currently considered reliable for gauging individual prognosis. $[1,7]$

Among scoring systems for peritonitis the Manheim peritonitis index and the Altona index are still in use as indicators of severity in cases of secondary bacterial peritonitis.[1,7] They enable appropriate classification of patients and comparison of those from different institutions.[10,11] More frequently used are nonspecific scoring systems for MAS, such as the Acute Physiology and Chronic Health Evaluation II (APACHE II), which is calculated within 24 hours of admission. It is widely used in intensive care and includes 12 physiological variables and laboratory tests not always available in all ICUs.[12] Additionally, its application is limited in assessing the effects of interventions on physiological variables in patients with peritonitis.[7] 
According to Ramsay, an ideal scoring system should quantify severity of surgical patients' risk of death or major complications, based on readily available objective data, and in a timely manner. It should be easy to use, clearly define the condition to be predicted, and be applicable for audit purposes.[13] Therefore, it would be useful to create prognostic scoring systems based on simple indicators routinely applicable in health services.

Several factors are involved in post-MAS clinical course whose relationship to mortality justifies their inclusion in scoring systems: age, malignancy (as a cause or comorbidity), acute impairment of vital physiological variables, failure to control focus of infection, and nutritional status,[7,14-22] Elevated intra-abdominal pressure (IAP) is an independent factor related to complications and death after MAS.[23-32] The fact that its measurement does not require major resources suggests it would be particularly useful in lowresource settings, but to date there have been no reports of its inclusion in predictive indices of mortality after MAS.

In short, there is no optimal scoring system for comprehensive assessment of individual patients after MAS. The objective of this study is to assess the utility of a model based on IAP for predicting death after MAS.

\section{METHODS}

Design and population A prospective observational cohort study was done from January 2008 through January 2010, with 389 patients in the period immediately following emergency or elective abdominal surgery, who had been admitted consecutively to the ICU of a university hospital connected to the General Calixto García Medical Faculty. Patients who remained in the ICU for $\geq 48$ hours were included. Excluded patients comprised 21 who died in the first 48 hours following surgery, 7 patients in whom transvesical IAP could not be measured (among them, 5 cases of pregnancy), 33 patients reoperated for noninfectious causes (because of their low influence on mortality in the postoperative period following MAS) and 28 patients with scheduled reoperations (due to the extent of their peritonitis, prognosis was already known to be poor). The final sample included 300 patients, who were assigned by simple random sampling to test and validation groups.

Variables The dependent variable was patient condition (alive or deceased) on discharge. Independent variables, selected for their association with MAS complications and mortality widely reported in the literature,[10-19,22-32] were:

- APACHE II, calculated by weighing results of variables that identify vital physiological impairment, from both physical examination (rectal temperature, mean arterial pressure, heart rate, respiratory rate) and ancillary tests (alveolar-arterial oxygen difference as fraction of inspired oxygen, arterial $\mathrm{pH}$, serum sodium, serum potassium, creatinine, hematocrit and white blood count), added to points assigned for age and chronic disease history;[12]

- age in completed years (included in APACHE II but with a low correlation, <0.6, and we were particularly interested in assessing its value as an independent factor);

- sex;

- presence of malignancy (reported or confirmed); and

- IAP (mmHg).

Data collection Pressure measurement (e.g., arterial blood pressure, central venous pressure) is an essential part of monitoring vital signs in ICU. It is a routine and simple practice in any ICU, commonly using a transducer with a graduated scale in centimeters of water, as for central venous pressure. To measure IAP in this study, instead of using a pressure transducer, a column of water with a centimeter scale was placed in the urine drainage system, using the technique described by Cheatham and Safcsak,[33] following recommendations by The Abdominal Compartment Society.[25] Two end-expiratory measurements were taken, six hours apart, within 24 hours of admission.

To control for measurement biases, ICU nurses were trained in the technique, which was duly standardized and always performed under specialist supervision. An intravesicular volume of $25 \mathrm{~mL}$ of saline solution was used in taking the measurement. Zero was placed at the axillary midline with the patient supine, using the superior iliac crest as a reference point.[25] Each IAP value was obtained via manometry $\left(\mathrm{cmH}_{2} \mathrm{O}\right)$ and recalculated as $\mathrm{mmHg}(1$ $\mathrm{cmH}_{2} \mathrm{O}=0.74 \mathrm{mmHg}$ ). The four values obtained for each patient were averaged and introduced into a database. Each patient was individually followed until hospital discharge (alive or deceased).

Data management and analysis For each quantitative variable (age, APACHE II and IAP) central tendency and dispersion measures were median and interquartile range, while frequencies and percentages were used for categorical variables (sex and malignancy). To verify between-groups similarity in categorical variables, the chi-square test with Yates correction for continuity was used, and the Fisher exact test when $25 \%$ or more of expected frequencies were $<5$. The Mann-Whitney $U$ test was used to compare differences in continuous variable medians among groups under basal conditions, since they were not normally distributed. Parameters of the logistic regression model were estimated in the test group and predictive capacity of the models for new patients was assessed in the validation group.

Three logistic regression models were fitted for predicting probability of death:

- Model I (APACHE II+IAP): mortality by age, sex, malignancy, APACHE II and IAP.

- Model II (APACHE II): mortality by age, sex, malignancy and APACHE II.

- Model III (IAP): mortality by age, sex, malignancy and IAP.

To assess the magnitude of associations, odds ratios (OR) and their $95 \%$ confidence intervals $(\mathrm{Cl})$ were calculated. The receiver operating characteristic (ROC) curve was used to assess the capacity of each model to discriminate between living and deceased patients in each group, taking into account sensitivity and specificity values for each point. The discriminative power of the model was considered excellent if the area under the curve (AUC) was $>0.80$, very good if it was $>0.75$, and good if it was $>0.70$.[34] Calibration of each model was assessed using the Hosmer-Lemeshow goodness-of-fit test, according to which, $p>0.05$ indicates acceptable model calibration.[35] ROC AUCs were compared using the chi-square test of homogeneity.

SPSS 11.5 was used for data organization, validation and analysis.

Ethics The protocol was approved by the General Calixto García Medical Faculty Ethics Committee. After receiving information about the study, patients or next-of-kin (of unconscious patients) provided written informed consent before inclusion in the 
study. IAP measurement did not interfere with other diagnostic or therapeutic procedures, in accordance with the Helsinki Declaration.[36]

\section{RESULTS}

Table 1 displays the general characteristics of the study sample by vital status at discharge. There were significant differences between alive and deceased patients according to sex, age, reoperation, IAP and APACHE II score.

Influence of model variables on probability of dying is shown in Table 2. According to OR and $p$ values, age was the variable with the most influence on probability of dying for the three models, APACHE II and IAP.

Table 3 displays validation of the three models, with practically identical results in the test and validation groups, with very good calibration (HosmerLemeshow $p>0.05$ ) and discrimination (AUC close to unity) and no significant differences in discrimination among the three models. The similarity between the test and validation groups is evidence of external validity.

\section{DISCUSSION}

Three models were developed and validated to predict mortality in post-abdominal-surgery patients admitted to the ICU. The three models demonstrate similar capacity to discriminate between survivors and nonsurvivors. AUC values were so close that no one model could be deemed superior to the others.

From a clinical point of view, IAP's contribution to the predictive value of the models containing it (IAP and APACHE II+IAP) is of great importance. IAP increases in physiopathological conditions and is $5-7 \mathrm{mmHg}$ in critical patients.[25] A sustained increase in IAP during the first postoperative week leads to organ and system dysfunction, which is significantly associated with higher mortality.[17,3739] Its effects on splanchnic circulation and on intraabdominal organ function lead to progressive failure of renal, cardiorespiratory and hepatic function. $[30,31,40,41]$ Intestinal mucosal damage due to mesenteric ischemia resulting from intra-abdominal hypertension leads to bacterial translocation and triggers multiple organ failure.[30,31,39-43] IAP magnitude reflects the cumulative effect of physiopathological impairments occurring after MAS.[23,24,37] For this reason, IAP adds specificity to the model and makes it recommendable for prediction of postoperative death in MAS patients, even though on its own, it is not comprehensive.

The IAP model was comparable in effectiveness to the one based on APACHE II, currently the most used scoring system for overall assessment of severity in critical patients.[16,18,37] As a predictive index, it enables assessment of extent of acute physiological impairment and weighs the influence of chronic diseases on patient status.[12] Its limitations are that it is not
Table 1: Characteristics of surgical patients by discharge vital status

\begin{tabular}{|c|c|c|c|c|}
\hline Variable & $\begin{array}{c}\text { Total } \\
n=300\end{array}$ & $\begin{array}{c}\text { Alive } \\
n=276(92 \%)\end{array}$ & $\begin{array}{c}\text { Deceased } \\
n=24(8 \%)\end{array}$ & p \\
\hline Male sex $(n, \%)$ & $188(62.7)$ & $182(65.9)$ & $6(25)$ & $<0.001^{a}$ \\
\hline Age (mean, SD) & $55.8(19.8)$ & $55.1(20.0)$ & $73.1(6.6)$ & $<0.001^{b}$ \\
\hline Comorbidity (n, \%) & $288(96.0)$ & $264(95.7)$ & $24(100.0)$ & $0.608^{c}$ \\
\hline Reoperation (n, \%) & $102(34.0)$ & $78(28.3)$ & $24(100.0)$ & $<0.001^{b}$ \\
\hline Malignancy (n, \%) & $13(4.3)$ & $12(4.3)$ & $1(4.2)$ & $1.000^{c}$ \\
\hline IAP (mmHg) (median, IQR) & $10(10)$ & $10(8)$ & $21(5)$ & $<0.001^{b}$ \\
\hline APACHE II (median, IQR) & $14(11)$ & $13(9)$ & $26.0(1)$ & $<0.001^{b}$ \\
\hline
\end{tabular}

atwo-tailed chi-square test with Yates correction ${ }^{\mathrm{b}}$ Mann-Whitney $\mathrm{U}$ test

Table 2: Probability of dying by study variable

\begin{tabular}{|c|c|c|c|c|c|c|}
\hline \multirow{2}{*}{ Variable } & \multicolumn{2}{|c|}{ APACHE II+IAP } & \multicolumn{2}{|c|}{ APACHE II } & \multicolumn{2}{|l|}{ IAP } \\
\hline & OR $(95 \% \mathrm{CI})$ & $p$ & OR (95\% CI) & $p$ & OR $(95 \% \mathrm{CI})$ & $p$ \\
\hline ge & $\begin{array}{r}1.44 \\
(1.06-1.95)\end{array}$ & 0.017 & $\begin{array}{r}1.26 \\
(1.08-1.48)\end{array}$ & 0.003 & $\begin{array}{r}1.21 \\
(1.08-1.35)\end{array}$ & 0.000 \\
\hline Sex & $\begin{array}{r}1.81 \\
(0.18-17.55)\end{array}$ & 0.608 & $\begin{array}{r}0.52 \\
(0.09-2.97)\end{array}$ & 0.465 & $\begin{array}{r}2.52 \\
(0.46-13.66)\end{array}$ & 0.282 \\
\hline Malignancy & $\begin{array}{r}0.72 \\
(0.03-15.53)\end{array}$ & 0.837 & $\begin{array}{r}0.14 \\
(0.01-1.86)\end{array}$ & 0.134 & $\begin{array}{r}1.92 \\
(0.13-27.29)\end{array}$ & 0.629 \\
\hline APACHE II & $\begin{array}{r}3.31 \\
(1.26-8.67)\end{array}$ & 0.015 & $\begin{array}{r}2.70 \\
(1.43-5.12)\end{array}$ & 0.002 & $\mathrm{~N} / \mathrm{A}$ & $\mathrm{N} / \mathrm{A}$ \\
\hline IAP & $\begin{array}{r}1.52 \\
(1.02-2.25)\end{array}$ & 0.038 & $\mathrm{~N} / \mathrm{A}$ & N/A & $\begin{array}{r}1.69 \\
(1.32-2.17)\end{array}$ & 0.000 \\
\hline
\end{tabular}

APACHE II: Acute Physiology and Chronic Health Evaluation II

IAP: intra-abdominal pressure N/A: not applicable

Table 3: Model validation

\begin{tabular}{l|c|r|r|r|}
\hline \multirow{2}{*}{ Model } & \multicolumn{2}{|c|}{ Hosmer-Lemeshow } & \multicolumn{2}{c|}{ ROC } \\
\cline { 2 - 5 } & Chi square & $p$ & AUC* & $95 \%$ Cl \\
\hline Test group & & & & \\
\hline APACHE II+IAP & 0.74 & 1.00 & 0.99 & $0.98-1.0$ \\
\hline APACHE II & 0.60 & 1.00 & 0.99 & $0.97-1.0$ \\
\hline IAP & 1.34 & 1.00 & 0.97 & $0.96-1.0$ \\
\hline Validation group & & & & \\
\hline APACHE II+IAP & 0.70 & 1.00 & 0.99 & $0.97-1.0$ \\
\hline APACHE II & 0.60 & 1.00 & 0.98 & $0.97-1.0$ \\
\hline IAP & 1.34 & 1.00 & 0.98 & $0.96-1.0$ \\
\hline
\end{tabular}

${ }^{*}$ chi square $2.80, \mathrm{df}=2, \mathrm{p}=0.094$

APACHE II: Acute Physiology and Chronic Health Evaluation II

AUC: area under the curve IAP: intra-abdominal pressure

ROC: receiver operating characteristic

specific to surgical patients, that it only uses information from the first 24 hours after admission, and that it does not consider response to therapy.[12,44]

IAP is an independent risk factor for surgical patient mortality, as has been demonstrated in a variety of studies, and can be measured at any point during the patient's illness, continuously or episodically.[23-32] These characteristics add specificity to the APACHE II model. In an interesting study, Reintam analyzed IAP and APACHE II as independent predictors of death in patients admitted to ICU, using univariate analysis and subsequently adding variables to a multiple regression analysis. He concluded that APACHE II at admission is the most sensitive predictor and 
that IAP and lactate values are also good independent predictors of mortality.[45]

Our findings suggest that combining APACHE II variables and IAP as prognostic factors in the same model permits a more comprehensive and objective approach to predicting mortality, since their strengths are complementary. From this point of view, the most comprehensive model is APACHE II+IAP, since it has APACHE Il's demonstrated utility in estimating magnitude of severity in the critical patient, $[16,18,37]$ along with IAP, which is very informative about progress in postlaparotomy patients.[44]

Our study has several limitations. It was done in a single facility, with a high volume of reoperated patients and high mortality, which could limit external validity. It must be remembered, however, that these are severely ill patients, with APACHE II scores $>13$ points, with mortality within permissible limits for the severity of their peritonitis.

All three models demonstrated validity for estimating probability of death in surgery patients treated in the ICU after abdominal surgery; i.e., they are reproducible in populations with similar characteristics. For practical reasons, the authors propose the IAP-based model, which is equivalent to the other two models in discriminative capacity, but is less expensive because it involves just one variable, does not require laboratory tests (like APACHE II), and follows the principle of parsimony, which is crucial in biomedical modeling.[46,47] The IAP-based model is the most economical and therefore the most applicable in conditions of low material and human resources and in contingency and disaster areas.

Clinical judgment is often biased by subjectivity, interindividual variability, lack of reproducibility and tendency to overestimate,[48] since it depends on physician experience, specific skills, and values. In the case of critical patients, psychic stress or case overload are almost always present and can increase the probability of bias when formulating a prognosis. These characteristics justify the need to rely on more objective, reliable and reproducible prognostic tools. Further studies should consider clinical validation of these results in other contexts, and explore automation, which would facilitate use of IAP to assess prognosis at the bedside.

\section{CONCLUSIONS}

The three models possess good capacity and similar effectiveness for prediction of discharge condition in MAS patients. Although the model based on APACHE II+IAP is a priori more comprehensive, the IAP model is more feasible, especially in limited-resource conditions. -1 -

\section{REFERENCES}

1. Sartelli M, Catena F, Abu-Zidan FM, Ansaloni L, Biffl WL, Boermeester MA, et al. Management of intra-abdominal infections: recommendations by the WSES 2016 consensus conference. World J Emerg Surg. 2017 May 4;12:22.

2. Pusajó JF, Bumaschny E, Doglio GR, Cherjovsky MR, Lipinszki Al, Hernández MS, et al. Postoperative intraabdominal sepsis requiring reoperation. Arch Surg. 1993 Feb;128(2):218-22.

3. Cheadle WG, Spain DA. The continuing challenge of intra-abdominal infection. Am J Surg 2003 Nov 28;186(5A):15S-22S

4. Bader FG, Schröder M, Kujath P, Muhl E, Bruch $\mathrm{HP}$, Eckmann C. Diffuse postoperative peritonitis - value of diagnostic parameters and impact of early indication for relaparotomy. Eur J Med Res. 2009 Nov 3;14:491-6.

5. Xiao Z, Wilson C, Robertson HL, Roberts DJ, Bal $C G$, Jenne CN. Inflammatory mediators in intraabdominal sepsis or injury - a scoping review. Crit Care. 2015 Oct 27:19:373.

6. Straatman J, Cuesta MA, Schreurs WH, Dwars BJ, Cense HA, Rijna H, et al. The PRECious trial PREdiction of Complications, a step-up approach, CRP first followed by CT-scan imaging to ensure quality control after major abdominal surgery: study protocol for a stepped-wedge trial Trials. 2015 Aug 28;16:382.

7. Sartelli M. A focus on intra-abdominal infections. World J Emerg Surg [Internet]. 2010 Mar 19 [cited 2017 Jun 19];5:9. Available from: http://www .wjes.org/content/5/1/9

8. La Rosa Armero Y, Matos Tamayo ME, Rodríguez Fernández Z. Características de las reintervenciones en un servicio de cirugía general. MEDISAN [Internet]. 2017 [cited 2017 Jun 19];21(2):192. Available from: http://medisan .sld.cu/index.php/san/article/view/1234/pdf. Spanish.

9. Giaccaglia V, Salvi PF, Cunsolo GV, Sparagna $\mathrm{S}$, Antonelli MS, Nigri G, et al. Procalcitonin, as an early biomarker of colorectal anastomotic leak, facilitates enhanced recovery after surgery.
J Crit Care [Internet]. 2014 Aug [cited 2017 Jun 19];29(4):528-32. Available from: http://dx.doi .org/10.1016/j.jcrc.2014.03.036

10. Wacha $\mathrm{H}$, Linder MM, Feldman U, Steinfensand RA. Mannheim Peritonitis Index: Prediction of risk of death from peritonitis. Construction of a statistical and validation of an empirically based index. Theoret Surg. 1987 Jan;1:169-77.

11. Biondo S, Ramos E, Fragealvitri D, Kreisler E, Ragué JM, Jaurrieta E. Comparative study of left colonic Peritonitis Severity Score and Mannheim Peritonitis Index. Br J Surg. 2006 May;93(5):616-22.

12. Knaus WA, Zimmerman JE, Wagner DP, Draper EA, Lawrence DE. APACHE acute physiology and chronic health evaluation a physiologically based classification system. Crit Care Med.1981 Aug;9(8):591-7.

13. Ramsay JR, Mac G, Murray GD. Prediction of surgical risk in adults. Surg Res Comm.1988;3:95103.

14. Koperna T, Schulz F. Relaparotomy in peritonitis: prognosis and treatment of patients with persisting intra-abdominal infection. World J Surg. 2000 Jan;24(1):32-7

15. Gil-Bona J, Sabaté A, Miguelena Bovadilla JM, Romà Adroer R, Koo M, Jaurrieta $E$. Valor de los índices de Charlson y la escala de riesgo quirúrgico en el análisis de la mortalidad operatoria. Cir Esp [Internet]. 2010 Sep 1 [cited 2017 Jan 5];88(3):174-9. Available from: http:// www.elsevier.es/es-revista-cirugia-espanola -36-articulo-valor-los-indices-charlson-escala -S0009739X10002897 - aff2. Spanish.

16. Torer N, Yorganci K, Elker D, Sayek I. Prognostic factors of the mortality of postoperative intraabdominal infections. Infection. 2010 Aug;38(4):255-60.

17. Martínez-Casas I, Sancho JJ, Nve E, Pons MJ, Membrilla E, Grande L. Preoperative risk factors for mortality after relaparotomy: analysis of 254 patients. Langenbecks Arch Surg. 2010 Jun;39(5):527-34
18. Berreta J, Kociak D, Balducci A, De Feo F, Laplacette MV, Bellido F, et al. Peritonitis secundaria generalizada: predictores de mortalidad, sobrevida y vinculantes evolutivos. Acta Gastroenterol Latinoam. 2010 Jun;40(2):105-16. Spanish.

19. Davis P, Hayden J, Springer J, Bailey J, Molinari $M$, Johnson P. Prognostic factors for morbidity and mortality in elderly patients undergoing acute gastrointestinal surgery: a systematic review. Can J Surg. 2014 Apr;57(2):E44-52. English, French.

20. Stommel MWJ, de Wilt JH, ten Broek RP, Strik C, Rovers MM, van Goor H. Prior Abdominal Surgery Jeopardizes Quality of Resection in Colorectal Cancer. World J Surg. 2016 May 6;40(5):1246-54

21. Kwak BJ, Kim SC, Song KB, Lee JH, Hwang DW, Park KM, et al. Prognostic factors associated with early mortality after surgical resection for pancreatic adenocarcinoma. Korean J Hepatobiliary Pancreat Surg. 2014 Nov;18(4):138-46.

22. Unver M, Fırat Ö, Ünalp ÖV, Uğuz A, Gümüs T, Sezer TÖ, et al. Prognostic factors in peptic ulcer perforations: a retrospective 14-year study. Int Surg. 2015 May;100(5):942-8.

23. Basu A, Pai DR. Early elevation of intra-abdominal pressure after laparotomy for secondary peritonitis: a predictor of relaparotomy? World J Surg. 2008 Aug;32(8):1851-6.

24. Khan S, Verma AK, Ahmad SM, Ahmad R. Analyzing intra-abdominal pressures and outcomes in patients undergoing emergency laparotomy. J Emerg Trauma Shock. 2010 Oct;3(4):318-25.

25. Kirkpatrick AW, Roberts DJ, De Waele J, Jaeschke R, Malbrain ML, De Keulenaer B, et al. Intra-abdominal hypertension and the abdominal compartment syndrome: updated consensus definitions and clinical practice guidelines from the World Society of the Abdominal Compartment Syndrome. Intensive Care Med. 2013 Jul; 39(7):1190-206.

26. Reyes de la Paz A, Lombardo Vaillant TA, Rubio Olivares DY. Valor predictivo de la presión intra-abdominal en el diagnóstico de com- 
plicaciones posoperatorias abdominales. Rev Cub Med Mil [Internet]. 2007 Oct-Dec [cited 2017 Apr 20];36(4). Available from: http://scielo sld.cu/scielo.php?script =sci arttext\&pid =S0138-65572007000400003. Spanish.

27. Sartelli M, Viale P, Catena F, Ansaloni L, Moore E, Malangoni M, et al. 2013 WSES guidelines for management of intra-abdominal infections. World J Emerg Surg. 2013 Jan 8;8(1):3.

28. Holodinsky JK, Roberts DJ, Ball CG, Blaser AR, Starkopf J, Zygun DA, et al. Risk factors for intraabdominal hypertension and abdominal compartment syndrome among adult intensive care unit patients: a systematic review and meta-analysis. Crit Care. 2013;17(5):R249.

29. Chow AW, Evans GA, Nathens AB, Ball CG, Hansen G, Harding GK, et al. Canadian practice guidelines for surgical intra-abdominal infections. Can J Infect Dis Med Microbiol. 2010;21(1):1137.

30. Sartelli M, Catena F, Di Saverio S, Ansaloni L, Malangoni M, Moore EE, et al. Current concept of abdominal sepsis: WSES position paper. World J Emerg Surg. 2014 Mar 27;9(1):22.

31. Leppäniemi A, Kimball EJ, De Laet I, Malbrain ML, Balogh ZJ, De Waele JJ. Management of abdominal sepsis - a paradigm shift? Anaesthesiol Intensive Ther. 2015;47(4):400-8.

32. Khan S, Verma AK, Ahmad SM, Ahmad R. Analyzing intra-abdominal pressures and outcomes in patients undergoing emergency laparotomy. J Emerg Trauma Shock. 2010 Oct;3(4):318-25.

33. Cheatham ML, Safcsak K. Intra-abdominal pressure: a revised method for measurement. J Am Coll Surg. 1998;186(5):594-5.

34. Swets JA. Measuring the accuracy of diagnostic systems. Science. 1988 Jun 3;240(4857):128593.

35. Hosmer DW, Lemeshow S. Applied Logistic Regression. New York: John Wiley \& Sons Inc.; 1989. $307 \mathrm{p}$

36. World Medical Association Declaration of Helsinki. Ethical principles for medical research involving human subject. 59th WMA General Assembly, Seoul, October 2008 [Internet]. Ferney-Voltaire (FR): WMA; 2008 [cited 2017 Apr 17]. Available from: http://irb.sinica.edu .tw/doc/regulation/DECLARATION\%20OF\%20 HELSINKI\%20\%282013\%29.pdf

37. Azoulay E, Afessa B. The intensive care support of patients with malignancy: do everything that can be done. Intensive Care Med, 2006 Jan;32(1):3-5

38. Hartl WH, Wolf $\mathrm{H}$, Schneider $\mathrm{CP}$, Küchenhoff $\mathrm{H}$, Jauch KW. Acute and long-term survival in chronically critically ill surgical patients: a retrospective observational study. Crit Care. 2007;11(3):R55.

39. Cheng J, Wei Z Liu X Li X Yuan Z, Zheng J, et al. The role of intestinal mucosa injury induced by intra-abdominal hypertension in the development of abdominal compartment syndrome and multiple organ dysfunction syndrome. Crit Care. 2013 Dec 9;17(6):R283.

40. Kirkpatrick AW, Roberts DJ, De Waele J, Laupland $\mathrm{K}$. Is intra-abdominal hypertension a missing factor that drives multiple organ dysfunction syndrome? Crit Care. 2014 Mar 19;18(2):124.

41. Hatipoglu S, Akbulut S, Hatipoglu F, Abdullayev R. Effect of laparoscopic abdominal surgery on splanchnic circulation: Historical developments. World J Gastroenterol. 2014 Dec 28;20(48):18165-76.

42. Smith M, Buddingh KT, Bosma B, Nieuwenhuijs VB, Hofker HS, Zijlstra JG. Abdominal Compartment Syndrome and Intra-abdominal Ischemia in Patients with Severe Acute Pancreatitis. World J Surg. 2016 Jun;40(6):1454 I-61.

43. Kirkpatrick AW, McBeth PB, Ball CG, Ejike JC, De Laet IE, Nickerson D. Mesenteric ischemia, intra-abdominal hypertension, and the abdominal compartment syndrome. Plastic Surg (Oakv). 2016 Spring;24(1):9-10.

44. Unalp HR, Kamer E, Kar H, Bal A, Peskersoy M, Ali Onal M. Urgent abdominal re-explorations. World J Emerg Surg. 2006 Apr 4;1:10.

45. Reintam A, Parm P, Kitus R, Kern H, Starkopf J. Primary and secondary intra-abdominal hypertension-different impact on ICU outcome. Intensive Care Med. 2008 Sep;34(9):1624-31.

46. Domínguez AH, Acuña Collazos JA, Toro Ocampo EM. Una comparación entre métodos estadísticos clásicos y técnicas metaheurísticas en el modelamiento estadístico. Scientia et Technica. 2012;(50):68-77. Spanish.

47. Pons JMV, Argimón JM. De la parsimonia en medicina. Med Clin [Internet]. 2013 Nov [cited 2017 May 5];141(9):387-89. Available from: http:// www.elsevier.es/es-revista-medicina-clinica -2-articulo-de-parsimonia-medicina-S00257753 1300359X. Spanish.

48. Carmelo Dueñas C. El juicio clínico en cuidado intensivo ¿Es útil para tomar decisiones y pre- decir pronósticos? [Internet]. Cartagena de Indias: Unidad de Cuidado Intensivo, Universidad de Cartagena; [cited 2017 April 17]; [about 2 screens]. Available from: http://www.angelfire .com/space2/fjr/221_juicio_clinico_en_uci.htm. Spanish.

\section{THE AUTHORS}

Caridad de Dios Soler-Morejón (Corresponding author: csoler@infomed.sld.cu),physician with dual specialties in internal medicine and intensive care, with a doctorate in medical sciences. Full professor and senior researcher, Hermanos Ameijeiras Clinical-Surgical Teaching Hospital ICU, Havana, Cuba

Tomás A. Lombardo-Vaillant, general surgeon with a master's degree in medical education. Full professor and associate researcher, Surgery Department, General Calixto García Medical Faculty, Havana, Cuba.

Teddy O. Tamargo-Barbeito, physician with dual specialties in family medicine and biostatistics and a doctorate in medical sciences. Full professor and senior researcher, Biostatistics Department, Hermanos Ameijeiras ClinicalSurgical Teaching Hospital ICU, Havana, Cuba.

Manu L.N.G. Malbrain, intensivist. Director, ICU and High Care Burn Unit, Ziekenhuis Netwerk Antwerpen, Antwerp, Belgium; ICU Director, University Hospital Brussels, Belgium; and professor, Faculty of Medicine, Vrije Universiteit Brussel, Brussels, Belgium.

Submitted: August 21, 2017

Approved for publication: September 6, 2017 Disclosures: None 